\title{
Removal of Antibiotics During the Anaerobic Digestion of Slaughterhouse Wastewater
}

\author{
Martha Noro Chollom $^{1 *}$, Sudesh Rathilal ${ }^{1}$, Feroz M. Swalaha ${ }^{1}$, Babatunde F. Bakare ${ }^{2}$, Emmanuel K. Tetteh ${ }^{1}$ \\ ${ }^{1}$ Department of Chemical Engineering, Durban University of Technology, Durban 4000, South Africa \\ ${ }^{2}$ Department of Chemical Engineering, Mangosuthu University of Technology Jacobs, Durban 4026, South Africa
}

Corresponding Author Email: 21144183@dut.ac.za

https://doi.org/10.18280/ijsdp.150310

Received: 20 November 2019

Accepted: 17 February 2020

\section{Keywords:}

anaerobic digestion, hydraulic retention time, fate and pathway, chemical oxygen demand, slaughterhouse wastewaters, veterinary antibiotics

\begin{abstract}
Antibiotics and other emerging contaminants are removed by wastewater treatment plants (WWTPs) to a certain extent. However, the removal mechanism is not well understood due to the fact that the majority of the WWTPs only focus on the occurrence of these contaminants in the influents and effluents and sometimes in the sludge. Understanding the removal pathway is therefore difficult. This study is aimed at investigating the removal pathways of selected veterinary antibiotics from wastewater. A laboratory scale upflow anaerobic sludge blanket (UASB) reactor was employed to treat synthetic wastewater to explore the removal efficiencies of five veterinary antibiotics with an initial concentration of $50 \mu \mathrm{g} / \mathrm{L}$. In a like manner, batch reactors were further used to evaluate the removal routes of the antibiotics. The UASB reactor was operated continuously under mesophilic conditions to evaluate its performance with regards to the removal of organics and at the same time monitor biogas production. Organic loading rate (OLR) was varied from 8 to $9.2 \mathrm{~kg} \cdot \mathrm{COD} \cdot \mathrm{m}^{-3} \cdot \mathrm{d}^{-1}$ while keeping the hydraulic retention time (HRT) constant at $12 \mathrm{~h}$. A COD removal efficiency higher than $75 \%$ was achieved at an OLR of $9 \mathrm{~kg}$.COD. $\mathrm{m}^{-3} \cdot \mathrm{d}^{-1}$, with a HRT of 12 hours. About $80 \%$ of the antibiotics were removed during the continuous processes, however, a distinctive pattern of removal was not observed. The kinetic studies using batch reactors showed that the removal route for the antibiotics was majorly adsorption to the sludge. Biodegradation occurred alongside adsorption but to a lesser degree. The kinetic data showed that the antibiotics followed a first order kinetic model with half-lives that ranged from 6 to 77 days.
\end{abstract}

\section{INTRODUCTION}

Antibiotics are used extensively in animal husbandry for the treatment and prevention of diseases $[1,2]$. These antibiotics are said to be used in large quantities. For example, in China, the total antibiotics that were used in 2013 was approximately 162,000 tons, $52 \%$ of which was consumed by animals. In the USA, of the 22,700 tons of antibiotics used annually, $50 \%$ is supposedly used for animal farming [2,3]. Even though these figures are available in some countries, the global estimates are difficult to approximate. The reason is due to the fact that there is inadequate information in many countries and also the method of data collection varies. However, a commonality that exists amongst these countries is the fact that a great increase in consumption is being observed with more than half of the antibiotics used for animals [3]. Puckowski et al. [3] further reiterate that a staggering $70 \%$ of all the veterinary pharmaceuticals consumed are antibiotics. The antibiotics are used for therapeutic and non-therapeutic purposes. The nontherapeutic purpose is primarily for the promotion of growth in swine, cattle and poultry $[4,5]$. The antibiotics administered to the animals are not fully utilised by them. It is reported that only $30 \%$ to $90 \%$ of most antibiotics are metabolised. The remaining unchanged parent compounds are discharged into soils as fertilizers, or from pasture reared animals which excretes feaces directly on lands. Other possible means are surface runoffs, and direct usage in aquaculture has been identified to contaminate the aquatic environment [3]. As a result, antibiotics have been detected in wastewater treatment plants, sludge and manures [2]. Therefore, it is essential to remove antibiotics in waste streams before their release into the receiving environments.

Swine production is usually carried out in large quantities such that the consumption of antibiotics is said to be high. The reason is due to the fact that these animals are crowded in confined rooms with the surroundings sometimes in unhygienic conditions. Therefore to prevent the spread of diseases, most farmers take to the use of antibiotics. Therefore, swine farms are known to be major sources for antibiotics entering into the environment.

Most treatment plants treating such waters use conventional methods which are said to partially remove these antibiotics from wastewaters [6]. However, previous studies by Gonzalez-Gil et al. [7] indicated that anaerobic treatment processes can effectively treat some wastewaters containing emerging contaminants to a certain extent. Other methods such as activated sludge, advanced oxidation, activated carbon adsorption, membrane separation technology and membrane bioreactor (MBR) technology, among others have shown considerable removal of these contaminants [8-10].

It is indicated that during the treatment process, some of the contaminants are adsorbed to the sludge, while others are biodegraded by the microorganisms and are subsequently discharged as effluent. Some are expelled without any form of treatment. Therefore the removal routes for these contaminants could be biodegradation, adsorption, 
volatisation or hydrolysis. To give an understanding of the removal routes it is important that experiments are carried out in controlled laboratory reactors. This will overcome the uncertainty that is presented when taking samples from wastewater treatment plants (WWTPs). A few pioneer works with some controlled laboratory reactors have been carried out. For example, Pérez et al. [11] investigated the removal of three sulphonamides at a low concentration of $20 \mu \mathrm{g} / \mathrm{L}$ in an activated sludge process and found out that biodegradation was the primary route of removal. Another study by Kim et al. [12] on the use of two laboratory sequencing batch reactors for the removal of tetracycline found that the removal route was adsorption

Overall, the information on the removal and fate of antibiotics in WWTPs is still limited. This is more important especially for WWTPs treating complex wastewaters and manures of animal origin due to the fact that these wastes are complex in nature and hence are more difficult to handle [13]. Therefore, the objectives of this study were (i) to investigate the removal efficiency of five veterinary antibiotics using an anaerobic upflow sludge blanket (UASB) reactor treating slaughterhouse wastewaters (ii) to investigate the elimination routes of the antibiotics using biodegradation and adsorption and finally, (iii) to evaluate the biodegradation kinetics for the target antibiotics.

\section{MATERIALS AND METHODS}

\subsection{Target antibiotics and other chemicals}

The target antibiotics considered in the study were: amoxicillin (AMO), ciprofloxacin (CIP), enrofloxacin (ENRO), sulfamethazine (SMZ) and chlortetracycline (TET), purchased from Sigma Aldrich. The mobile phases: Methanol and Acetonitrile (CHROMASOLV®, HPLC grade) were purchased from Merck. Ultrapure water $\left(>18 \mathrm{M} \Omega \mathrm{cm}^{-1}\right)$ was obtained from the Millipore system. Formic acid (>99\%) and Ethylene diamine tetra acetic acid disodium ( $\mathrm{Na}_{2}$ EDTA) (>98\%) were purchased from Sigma Aldrich. Hydrochloric acid $(\mathrm{HCl})$ and Sodium Hydroxide $(\mathrm{NaOH})$ for $\mathrm{pH}$ adjustment were purchased from Associated Chemical Enterprise (ACE), South Africa. For decontamination purposes, all plastics and glassware were cleaned with soap water, soaked in $20 \%$ (v/v) nitric acid (also from ACE), rinsed with water again and dried before use. All chemicals used for the HPLC analysis were of analytical grade.

\subsection{Description of the reactor set-up}

The reactor was constructed from Plexiglas glass with an effective working volume of $4.5 \mathrm{~L}$. This comprised of three zones: the feed entrance zone, the sludge and blanket zone and the settling zone as depicted in Figure 1. An inverse cone which served as the gas-liquid-solid separator (GLS) was installed at the top portion of the sludge bed to enhance the separation of the biogas from the liquids and solids. To reduce variations in temperature, continuous recycling of cooling water through the water jacket of the reactor was carried out using the Grant stirred thermostatic circulators water-bath (GD120). The reactor had four sampling points which were used for the monitoring of sludge production as well as for desludging of the reactor. There was no recirculation of the effluent.

\subsection{Continuous operation of the UASB reactor}

The reactor was started with a digested sludge obtained from a wastewater treatment plant treating slaughterhouse wastewater from an abattoir in South Africa. The reactor was inoculated with $3 \mathrm{~L}$ of the activated sludge which was about two thirds of its working volume. Sludge was characterised to have a total suspended solids of (TSS) of $19.4 \mathrm{~g} \mathrm{~L}^{-1}$ and volatile suspended solids (VSS) of $13.8 \mathrm{~g} \mathrm{~L}^{-1}$. The digester was fed on a continuous basis at a flowrate of $0.25 \mathrm{~L} / \mathrm{hr}$ from the bottom of the reactor by the use of a Cole palmer masterflex peristaltic pump (Model 77521-50) at the rate defined by the hydraulic retention time (HRT) of $12 \mathrm{~h}$. However, for the first three days of the start-up, the reactor was operated in a batch mode at an HRT of 24 hours and thereafter, the continuous mode was used. An organic loading rate (OLR) of $1.54 \mathrm{~kg} \mathrm{~m}^{-3} d^{-1}$ was used for the first 3 days to enable stabilisation of the reactor, and thereafter, the OLR was increased stepwise as the treatment efficiency of the reactor improved with time. After the start-up period of the anaerobic reactor, the reactor was then run in a continuous process. The antibiotics mixture was added to the reactors, at an initial concentration of $50 \mu \mathrm{g} / \mathrm{L}$, and effluent was collected and analysed using an ultrafast high-performance liquid chromatography (UHPLC) with an SPD-M20A-Photodiode Array detector (PDA) described in our previous work [8].

The biogas produced was channeled through the gas outline as shown in Figure 1 and was passed through $3 \mathrm{M} \mathrm{NaOH}$ solution so as to capture the $\mathrm{CO}_{2}$ present in the biogas [14]. The biogas present was measured volumetrically by the displacement of water as shown in Figure 1. The produced gas was measured on a daily basis to enable the ease in which the system kinetics was followed. To obtain a stable operation of the reactor, the temperature of the reactor was maintained at $35^{\circ} \mathrm{C}$ with the use of a water bath. Reactor efficiency was evaluated by monitoring the removal of organics using Eq. (1). Table 1 shows the operational phases of the reactor.

$$
\text { Reactor eff ciency }=\left(1-\frac{C O D_{\text {out }}}{C O D_{\text {in }}}\right) \times 100
$$

Table 1. Operational phases of the reactor

\begin{tabular}{|c|c|c|c|}
\hline $\begin{array}{l}\text { Operational } \\
\text { Phase (days) }\end{array}$ & COD $(\mathrm{mg} / \mathrm{L})$ & 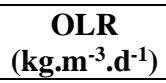 & HRT (Hrs) \\
\hline I (1-15) & $1000-1500$ & $2.8-3$ & $\begin{array}{c}\text { First three } \\
\text { days } 24 \\
\text { hours and } 12 \\
\text { hours } \\
\text { thereafter }\end{array}$ \\
\hline II (16-48) & $1500-2500$ & $\begin{array}{c}3.7-4.4 \\
51-6\end{array}$ & $\begin{array}{l}12 \\
12\end{array}$ \\
\hline IV (72-150) & $4000-5000$ & $6.1-9.2$ & 12 \\
\hline $\mathrm{V}(151-200)$ & 5000 & $6.1-9.2$ & 12 \\
\hline
\end{tabular}

Phases I and II indicate the start-up of the reactors. Phases III and IV indicate the period of reactor stabilization. The influent concentration was gradually increased from $20 \%$ after two weeks of start-up and gradually by $40 \%$ until eventually $100 \%$ of the prepared synthetic feed was introduced into the reactor. This method was adopted from Cao and Mehrvar [15]. 


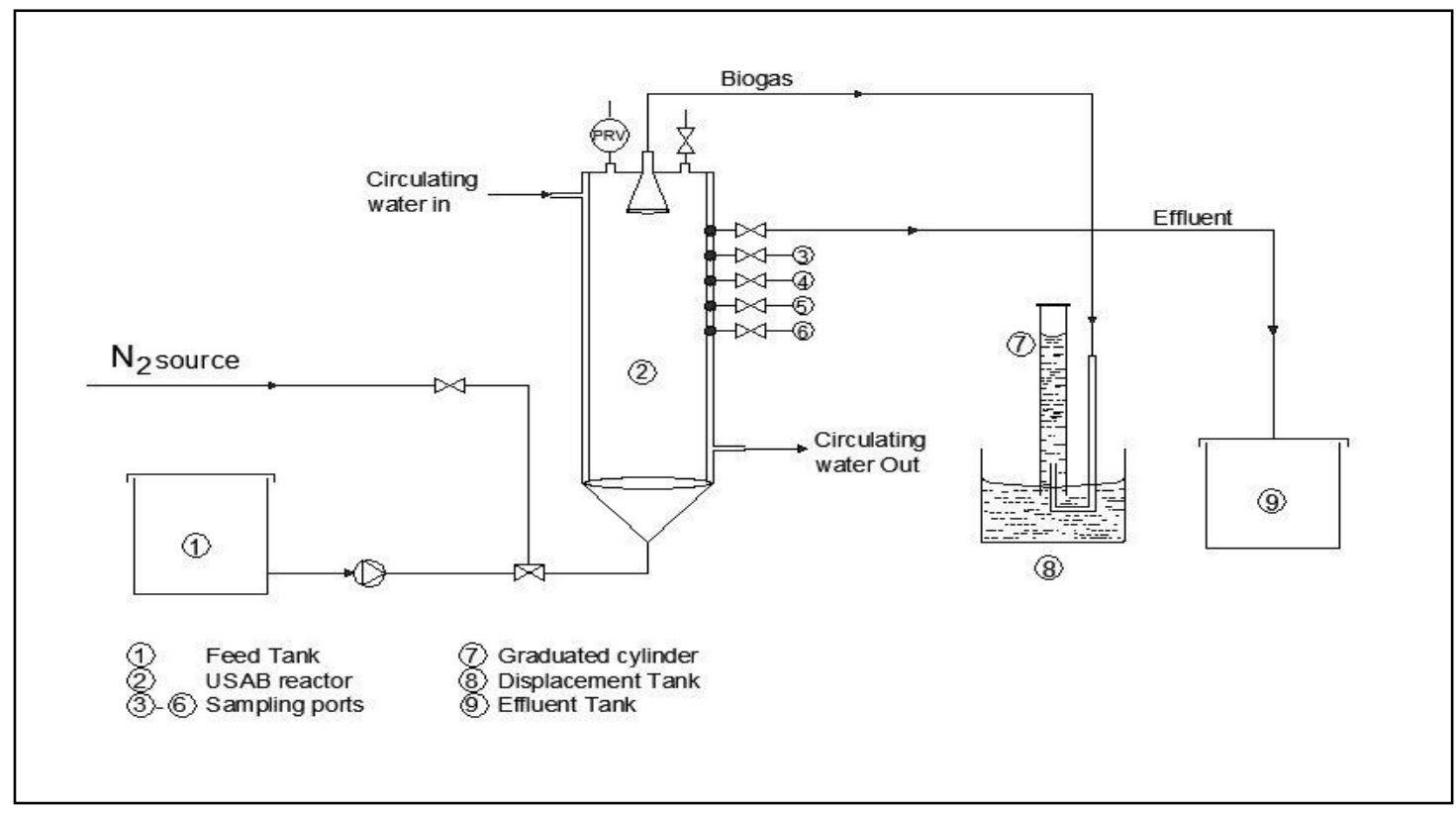

Figure 1. Schematic diagram of the experimental set-up [13]

\subsection{Analytical methods}

The following physico-chemical properties were determined: chemical oxygen demand (COD), TSS, VSS, total solids (TS), pH, volatile fatty acids (VFA) and alkalinity. The parameters were evaluated following the procedure for standard methods for the examination of water and wastewater [16]. Both TSS and VSS were determined by drying of homogenised samples at $103^{\circ} \mathrm{C}$ for $24 \mathrm{~h}$ for TSS and VSS was obtained by incinerating the dried fractions in a muffle furnace at $550^{\circ} \mathrm{C}$ for $1 \mathrm{~h}$. COD was determined using close refluxing according to the standard method 5220D. The $\mathrm{pH}$ and temperature were measured using a $\mathrm{pH}$ meter (Orion) and thermometer respectively. The $\mathrm{pH}$, temperature and COD were analysed every day during the start-up of the reactor. Targeted antibiotics were analysed with the UHPLC. Biogas production was monitored on a daily basis.

\subsection{Batch experiments using serum bottles}

Batch experiments were carried out to give an insight into the removal pathway of the antibiotics. The following were considered: adsorption, hydrolysis and biodegradation. Experiments were therefore carried out in serum bottles. The following was used: sludge (un-treated) and freeze dried (treated). To the freeze dried, sodium azide $\left(\mathrm{NaN}_{3}\right)$ was added and also actual wastewater and synthetic wastewater. Finally, mixed solutions of the antibiotics were used for the studies.

\subsection{Preparing of freeze dried activated sludge}

Collected digested sludge as previously described in the start-up was used in this section. $30 \mathrm{~mL}$ of the sludge was weighed into $50 \mathrm{~mL}$ centrifuge vials and were then centrifuged at $5000 \mathrm{~g}$ for $5 \mathrm{mins}$. The supernatant was discarded. The solid pellets were then shaken and thoroughly rinsed with deionised water repeatedly. The samples were further centrifuged for another $5 \mathrm{~min}$ and the process of rinsing was repeated. The sludge was thereafter suspended in the synthetic feed and allowed to acclimatise.

\subsection{Biodegradation and adsorption studies using wastewaters and sludge}

To elucidate the degradation pathway of the antibiotics, batch experiments were carried out using $250 \mathrm{~mL}$ serum bottles, where the working volume was $150 \mathrm{~mL}$. The bottles were dosed with the standard solution of the mixed compounds and the pre-determined amounts of sludge and wastewater was added to it where necessary. To ensure that there was no interference with oxygen, the bottles were purged with nitrogen before loading and after loading. The headspace was again flushed with nitrogen. After flushing, the bottles were sealed with gas-tight silicone septa and a crimping tool with aluminium rings. The sealed bottles were incubated at $35^{\circ} \mathrm{C}$ throughout the batch process time ( 28 days). They were shaken at a low speed of $100 \mathrm{rpm}$. The initial antibiotics concentration was $100 \mathrm{ppm}$. Table 2 shows the experimental design for the batch experiments. Samples were collected at the following times $0,0.5,1,2,4,8,10,15,20$ and 28 days. The chosen time of 28 days was adapted from a related study by Wang et al. [17]. The initial and final COD was measured as an indicator of the biological activity. Other authors have used caffeine which is a biodegradable compound to evaluate for bioactivity $[17,18]$. For the inhibition of biological activities, $0.1 \%$ Sodium azide $\left(\mathrm{NaN}_{3}\right)$ was added to selected serum bottles. All the bottles used for the studies were wrapped with aluminium foil to avoid possible photolysis of the compounds.

Reaction pathways are indicated as shown below.

B: biodegradation

A: Adsorption

$\mathrm{H}$ : Hydrolysis

$\mathrm{R}$ (Symbol for reactor number) and $\mathrm{R}^{\prime}$ (duplicate)

Chemical oxygen demand (COD)

Sorption efficiency as well as COD reduction were calculated according to Eq. (2) [19].

$$
\% \text { COD reduction }=\frac{\left(C_{o}-C_{t}\right) 100}{C_{o}}
$$


Table 2. Experiment design for the batch experiments

\begin{tabular}{cccccc}
\hline Treatment & Treated sludge & wastewater & antibiotics & $\mathbf{0 . 1 \%}$ NaN3 $_{3}$ & Removal routes \\
\hline R1: R1' & Yes & Yes & Yes & No & B+A+H \\
R2 & No & Yes & Yes & No & H \\
R3: R3' & Yes & Yes & yes & yes & A \\
R4 (control) & Yes & Yes & No & No & B \\
\hline
\end{tabular}

\subsection{Biodegradation kinetics models}

A biodegradation kinetic model (first order model) was applied for the biodegradation data as represented in Eq. (3). First order models were applied because the concentration of the antibiotics studied for the biodegradation tests were low $[17,18]$.

$$
\frac{d C}{d t}=-K_{1} \cdot C_{t} \Leftrightarrow C_{t}=C_{0} \cdot e^{-k \cdot t}
$$

where, $C_{0}$ is the initial concentration of the antibiotic; $C_{t}$ is concentration of the antibiotic at time $\mathrm{t} ; K_{1}$ is the first order rate constant. The half-lives of the compounds $t_{1 / 2}$ were calculated from Eq. (3) to give $\frac{(\ln 2)}{K_{1}}$.

\section{RESULTS AND DISCUSSION}

\subsection{Reactor start-up and performance}

The reactor start-up is reported as the period taken for stable operation of the reactor to occur. During this stage, the microorganisms are being acclimatised to the new environmental conditions and substrate. An equilibrium is also slowly being established between the various microorganisms present in the system, until the biomass is stable and efficient to degrade the substrate at the targeted OLR [20,21]. Reactor start-up has been reported as a complicated process, and as such the monitoring of both environmental and operating conditions is important [21].

The VSS/TSS is significant because it is an indication of the amount of biomass in the total sludge measured as suspended solids. A high ratio of VSS/TSS in the inoculum to be used for the reactor start-up is important [22]. For the start-up, the $\mathrm{VSS} / \mathrm{TSS}$ ratio was about 0.71 . This ratio continued to increase, which is an indication of the microorganism's adaptation and multiplication. Feed concentration of less than $3000 \mathrm{mg} \mathrm{L}^{-1}$ of COD $\left(2.8 \mathrm{~kg} \mathrm{~m}^{-3} \mathrm{~d}^{-1}\right)$ was used for the start-up to help in preventing and controlling the excessive generation of VFA since at this stage the microorganisms were still adapting to the new environment. Table 3 shows the COD removal as well as the biogas production. During the start-up of the reactor, both COD removal and biogas production were low. This is due to the fact that the microorganisms were adapting to the environment. Factors such as the water chemistry, HRT, pH and temperature amongst others are all crucial at this point. However, once the microorganisms were adapted to the reactor conditions, an increase in the COD removal and biogas production was noticeable.

The removal of COD was seen to be increasing as the reactor stabilised. COD removal was between $40-80 \%$. This implied that the presence of the antibiotics did not affect the performance of the microorganisms significantly. The initial concentration of the antibiotics as influent into the reactor was $50 \mu \mathrm{g} / \mathrm{L}$. The concentration of the influent containing the antibiotics was maintained at $50 \mu \mathrm{g} / \mathrm{L}$, unlike in other studies where the concentration was varied. Some of those studies evaluated the point at which the biological system becomes inhibited by the presence of the antibiotics. For example, Chelliapan et al. [23] varied the concentration of Tylosin in the pharmaceutical wastewater from 20 to $200 \mathrm{mg} / \mathrm{L}$ and Meng et al. [24] also varied the concentration of Amoxicillin in the pharmaceutical wastewater from 20 to $200 \mathrm{mg} / \mathrm{L}$. The general findings from most of the studies indicate that the initial concentration of the contaminants (antibiotics) had a relatively minor influence on the removal of COD and other organics from the treated wastewaters. Similarly, biogas production (methane and other gases) is not impacted on greatly even at high concentrations of the antibiotics [6, 24, 25].

Therefore, varying the concentration of the antibiotics does not really have a significant effect on the performances of the biological systems. The spiking of the reactor with the antibiotics did not show considerable effects on the performance of the reactor. However, a wide range of differences have been reported on the performance of anaerobic systems treating this kind of wastewater in a review by Cheng et al. [26]. The main reasons stated for the variation was the different antibiotic concentrations and types as well as the combination of different antibiotics used for these studies. On the effect of antibiotics combination, Feng et al. [6] observed that a combination of erythromycin-tetracyclinesulfamethoxazole (ETS), sulfamethoxazole-tetracycline (ST), erythromycin-sulfamethoxazole (ES) and erythromycintetracycline (ET)) had more serious inhibition than the individual antibiotics on the COD utilization and methane production. Similarly, they also found that the inhibition of the anaerobic processes could be only at very high concentrations. With regards to the effect on the biogas (methane) produced, a different scenario is presented. Some reports have indicated a reduction in the gas produced. This was explained by the bactericidal characteristics that kill bacteria instead of inhibiting bacterial growth at high concentrations, which is very different to bacteriostatic characteristics at lower concentrations $[6,26]$.

Table 3. Efficiency of the UASB on COD removal and biogas production

\begin{tabular}{ccccc}
\hline Phase & $\begin{array}{c}\text { Inlet COD } \\
(\mathbf{m g} / \mathbf{L})\end{array}$ & $\begin{array}{c}\text { Outlet COD } \\
(\mathbf{m g} / \mathbf{L})\end{array}$ & $\begin{array}{c}\text { Removal } \\
\mathbf{( \% )}\end{array}$ & $\begin{array}{c}\text { Biogas } \\
(\mathbf{m L} / \mathbf{d a y})\end{array}$ \\
\hline I & 1500 & 897 & 40 & 180 \\
II & 2136 & 1247 & 42 & 193 \\
III & 3051 & 1108 & 64 & 255 \\
IV & 3871 & 987 & 75 & 365 \\
V & 4869 & 1257 & 74 & 380 \\
V & 4743 & 1104 & 77 & 397 \\
V & 4821 & 1021 & 79 & 381 \\
V & 4825 & 1023 & 79 & 450 \\
\hline
\end{tabular}

\subsection{Antibiotics removal in the continuous process}

Figure 2 shows the removal of the antibiotics during the 
continuous operation of the reactor. It was observed that removal rates for each of the antibiotics differed.
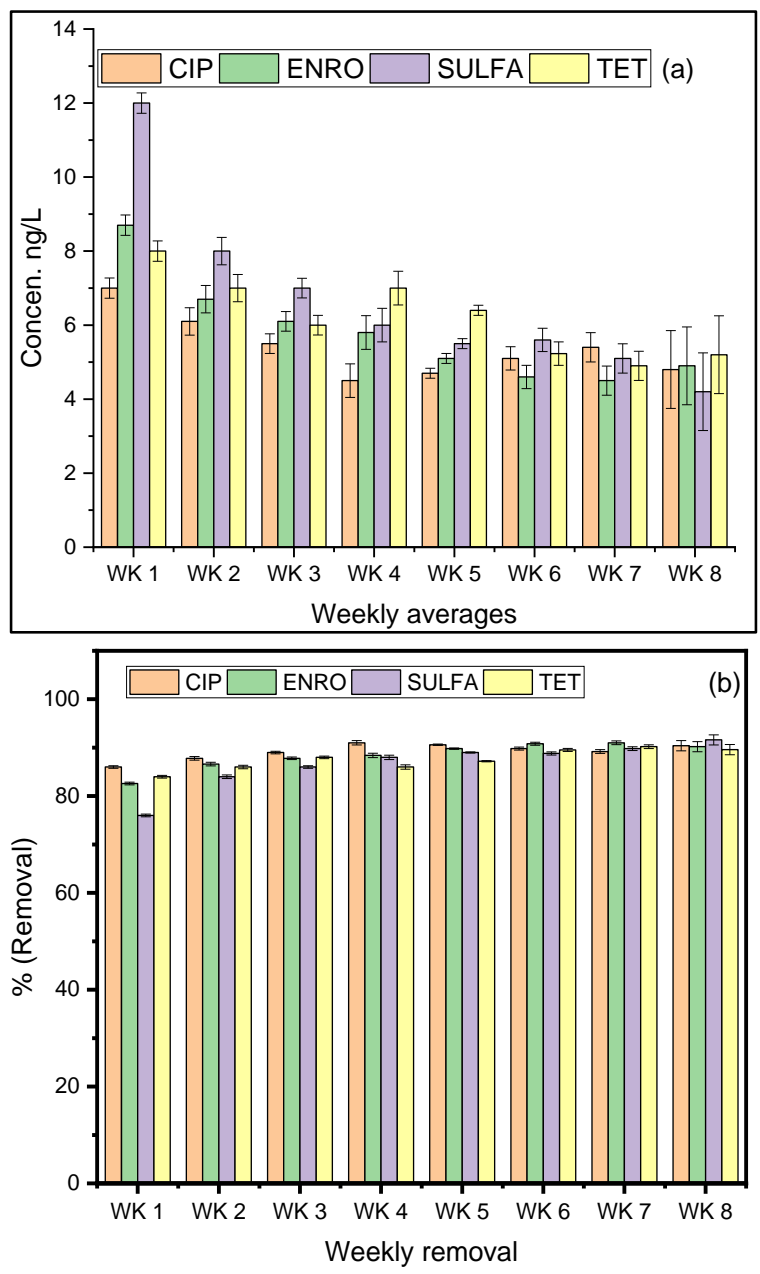

Figure 2. Remnant of the antibiotics in effluent expressed in $\mathrm{ng} / \mathrm{L}$ (a) and the percent removal (b) of the antibiotics in the effluent from the continuous process

Although the remnant of the antibiotics was in most cases less than $10 \mathrm{ng} / \mathrm{L}$ representing over $80 \%$ removal, a distinctive pattern could not be established. This was expected due to the differences in the chemical structures as well as the characteristics of the various antibiotics. The removal mechanism could have been biodegradation by the microorganisms or adsorption to the sludge. Therefore the pathway of removal was not easily established during the continuous treatment. Feng et al. [6] studied the removal of antibiotics from swine manure and reported a similar observation. In their study, they observed different removal patterns. Some of the studied antibiotics were rapidly removed while it took others longer or were found to still persist in the effluent without any form of removal.

\subsection{Removal of antibiotics using anaerobic batch reactors}

The removal of antibiotics could follow different pathways during wastewater treatment. One of the following could occur: adsorption, hydrolysis, volatisation or biodegradation [18]. Biodegradation and adsorption were the main pathways considered for this study. In the preliminary study, no hydrolysis was observed. Similarly, volatilisation did not occur as well, due to the fact that the antibiotics had low Henry Law constants and the presence of different polar and ionisable groups [27]. For the biodegradation and adsorption, the experimental design that was followed was elaborated in Table 2. A total of 6 serum bottles (anaerobic reactors) were used for the study, and are represented as R1 to R6.

\subsection{Biodegradation Kinetic studies}

Some of the studied antibiotics are known to be broad spectrum. However, the chosen concentration used for this study was not in the range to inhibit the microorganisms. A previous study on the inhibition of microorganisms by the fluoroquinolones (FQs) was carried out with concentrations varying from $100 \mu \mathrm{g} / \mathrm{L}$ to $40 \mathrm{mg} / \mathrm{L}$ by Wang et al. [17]. Despite the high concentrations used, inhibition of the microorganisms was not observed by them. The concentration used in this study was much lower. Also the observation made on the COD reduction was an indication that the microorganisms were not inhibited.

\subsection{Chemical oxygen demand (COD) removal}

Figure 3 shows the changes in COD occurring during biodegradation in the control reactor. The reduction of the COD therefore confirms the microbial activity of the microorganisms.

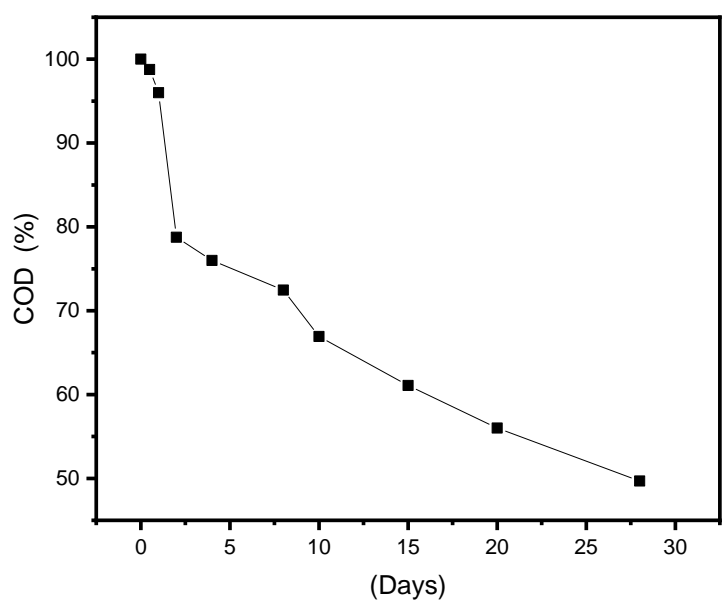

Figure 3. COD reduction in the control reactor during the biodegradation experiment at $100 \mathrm{rpm}$ and $35^{\circ} \mathrm{C}$

Some studies have used sodium Azide $\left(\mathrm{NaN}_{3}\right)$ to inhibit microorganisms in biological reactors [18]. Comparisons between the reactors with the $\mathrm{NaN}_{3}$ and the control found that no change in the COD had occurred in the reactor with the $\mathrm{NaN}_{3}$, thus suggesting inhibition has occurred. However, a reduction in COD with time was observed with the control reactor, thus indicating an occurrence of biodegradation in that reactor. Reduction in COD with time was observed to be decreasing, thus indicating the activeness of the microbial organisms.

\subsection{Removal of amoxicillin}

From batch experiments, it was observed that AMO was removed by both adsorption and biodegradation. By the end of 28 days, the biodegradation rate was about $80 \%$ while the adsorption was less than $60 \%$ as shown in Figure 4 . Therefore for the AMO, more than half of the initial influent concentration was removed during biodegradation. 


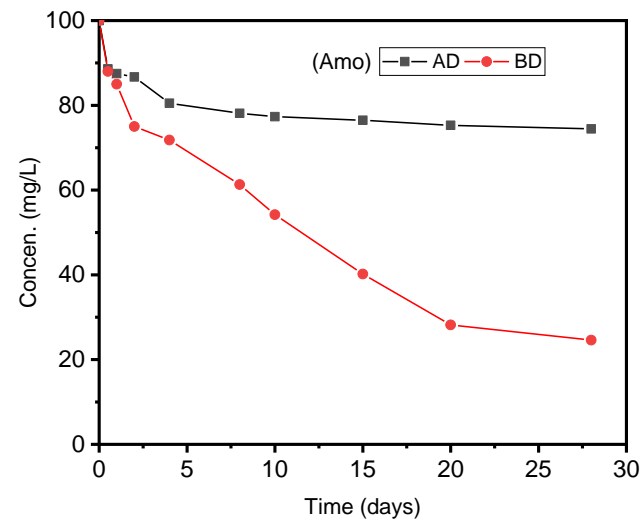

Figure 4. Biodegradation and Adsorption of AMO (AD refers to adsorption and $\mathrm{BD}$ refers to Biodegradation)

The mechanism of the removal for AMO was observed to be majorly biodegradation. This observation is in agreement with that made by Andreozzi et al. [28]. They found a 90\% removal of AMO through biodegradation and adsorption in 5 $\mathrm{h}$ in standardized batch tests using activated sludge, and the removal was dominated by biodegradation. However, Li and Zhang [18] made a different observation. In their study, they found that both adsorption and biodegradation mechanisms occurred during the wastewater treatment, with adsorption occurring at a faster rate. The differences in the removal mechanism could have been due to the wastewater characteristics or other operational factors.

AMO is part of the $\beta$-Lactam class. Their removal from wastewater using activated sludge has shown peculiar behaviour as compared to other antibiotics. The limited studies on the fate of the $\beta$-Lactams in wastewater treatment have been observed to vary considerably. This is possibly due to their different chemical structures, such as the variable side chains [18].

\subsection{Removal of fluoroquinolones}

Figure 5 shows the adsorption to sludge and the biodegradation of the Fluoroquinolones (FQs). For the fluoroquinolones (FQs); CIP and ENRO, the adsorption to sludge was much higher as observed from the mass balances. Both adsorption and biodegradation were observed, however, adsorption was dominant. Adsorption was about $80 \%$ for both FQs; while biodegradation was about $38 \%$. The biodegradation of the compounds was much lower than adsorption.

The adsorption of the FQs started very fast, but was seen to decrease with time. A previous report by Li and Zhang [18] on the biodegradation of FQs indicated that adsorption was the main pathway of their removal from fresh-water sewage treatment systems, with negligible biodegradation. Also Dorival-Garcí et al. [27] observed that biodegradation of the FQs by nitrifying bacteria in activated sludge resulted in less removal as compared to sorption.

Sorption to sludge has been presented as the most important mechanism through which the FQs are removed from wastewaters. This high affinity to the sludge is due to a number of factors such as partition coefficient $\left(\mathrm{K}_{\mathrm{d}}\right)$. A $\mathrm{K}_{\mathrm{d}}$ value of $>$ $300 \mathrm{~L} / \mathrm{kg}$ is said to be significant and can therefore easily be sorbed to a solid. The calculated amount for the FQs $\mathrm{K}_{d}$ in this study was from 629 to $1143 \mathrm{~L} / \mathrm{kg}$. Different values have been reported by various researchers. For example, Dorival-García et al. [27] obtained values between 530 to $1400 \mathrm{~L} / \mathrm{kg}$. The differences could be due to the different experimental conditions and the sludge characteristics. In another study by Li and Zhang [18] a high correlation between the $K_{d}$ values and the sorption of FQs to sludge was observed.

Further still, the octanol-water partition coefficient (Kow) is another factor that can be used to assess the hydrophobic sorption for uncharged molecules. Uncharged antibiotics with low $\log$ Kow $<2.5$ are considered to have low sorption potential [27].

The studied FQs have low octanol-water coefficients in contrast to the high $\mathrm{K}_{\mathrm{d}}$ values and as a result, the sorption ability was much stronger than the hydrophobic properties. Therefore, according to Dorival-García et al. [27], the hydrophobic partitioning is unable to drive the sorption of charged antibiotic molecules. Thus, the sorption of the FQs was higher than the biodegradation.
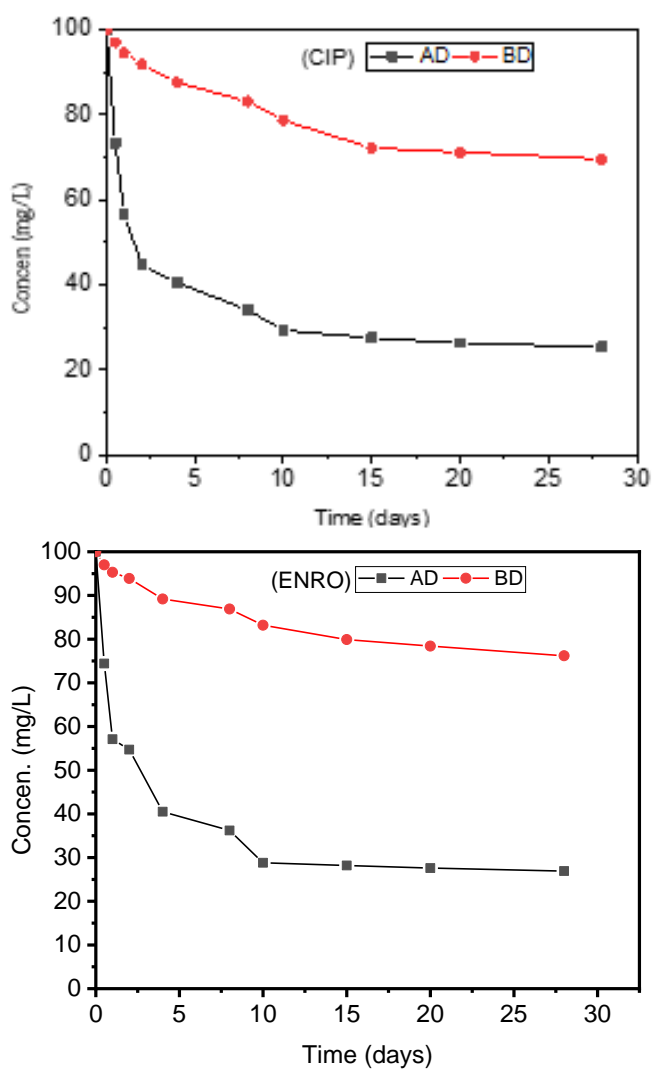

Figure 5. Biodegradation and Adsorption of CIP and ENRO (AD refers to adsorption and BD refers to Biodegradation)

\subsection{Removal of Sulfamethazine and Tetracycline}

Figure 6 shows the behaviour of SULFA and TET to biodegradation and adsorption.

For SULFA, both adsorption and biodegradation values were lower than those of the other studied compounds, however, the adsorption was observed to be higher than the biodegradation. The adsorption capacity of SULFA to sludge was $49 \%$ and biodegradation was $37 \%$.

The poor adsorptive properties of SULFA to the sludge can be explained by the acid-base equilibrium processes involved. SULFA which is a class of the sulphonamides is amphoteric. The functional groups are in an anionic form at neutral and basic $\mathrm{pH}$, resulting in a low adsorption to the activated sludge [29]. 
For TET, the biodegradation was lower (29\%) and adsorption was higher $(83.8 \%)$ by the end of the 28 days. TET showed a higher adsorption capacity to the sludge as compared to the other antibiotics. This suggests that the TET is not easily biodegraded, thus sorption is the main removal mechanism. These findings are in agreement with the findings by Li and Zhang [18]. Also, Shi et al. [30] observed that the removal of TET can be quick adsorption and slow biodegradation.
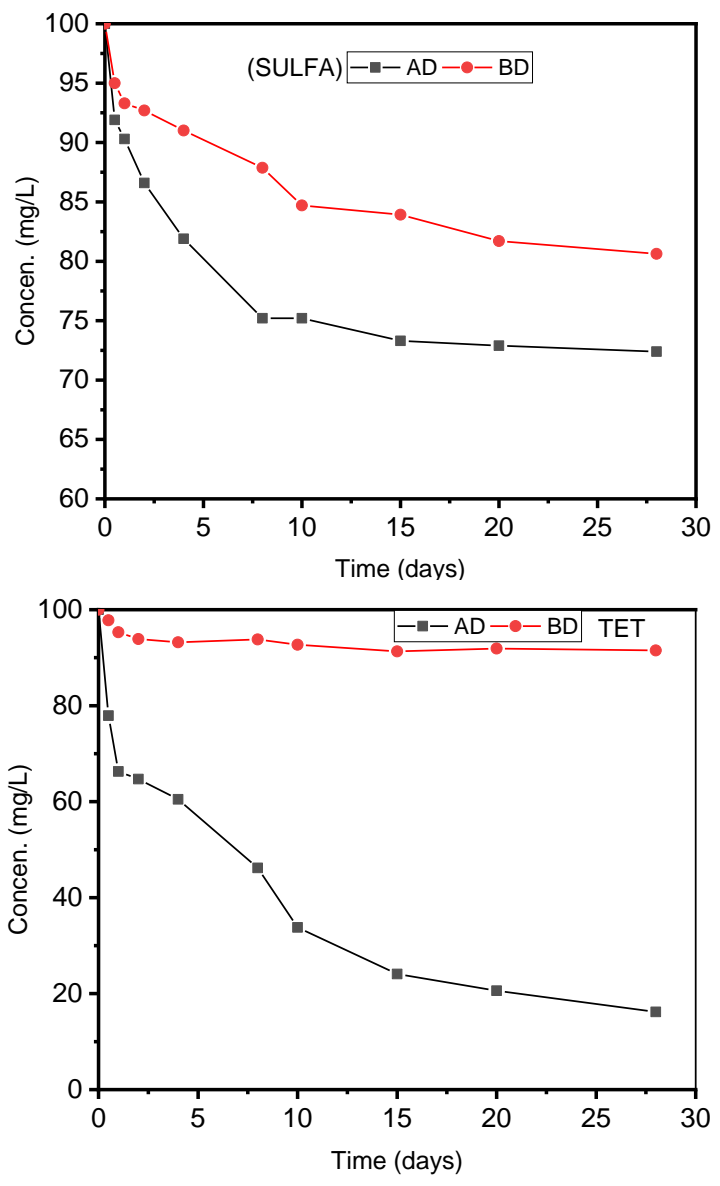

Figure 6. Biodegradation and Adsorption of SULFA and TET (AD refers to adsorption and BD refers to Biodegradation)

\subsection{Biodegradation kinetics}

The biodegradation of contaminants in trace amounts in sewage during biological treatment has been shown to follow the first-order kinetics model. This is due to the low concentration of the contaminants as compared to the biomass concentration [18].

Table 4 shows the kinetic parameters that were obtained from the plot of the natural logarithm of the ratio concentration at time $t$ and the initial concentration (starting concentration).

Table 4. Slope (k) of the linear regression, regression coefficient $\left(\mathrm{R}^{2}\right)$, and half-life of the antibiotics from the batch biodegradation studies

\begin{tabular}{cccc}
\hline Antibiotics & $\mathbf{k}$ & $\mathbf{t}_{\mathbf{1} / \mathbf{2}}$ (days) & $\mathbf{R}^{\mathbf{2}}$ \\
\hline AMO & 0.11 & 6.33 & 0.982 \\
CIP & 0.065 & 10.66 & 0.969 \\
ENRO & 0.053 & 13.08 & 0.983 \\
SULFA & 0.022 & 34.65 & 0.964 \\
TET & 0.009 & 77.01 & 0.816 \\
\hline
\end{tabular}

It is observed that almost all the antibiotics followed the first order degradation with coefficients of correlations $\left(\mathrm{R}^{2}\right)$ close to unity, except TET which was a little lower. AMO had the lowest half-life followed by the FQs (CIP and ENRO). SULFA and TET had the highest half-lives, thus signifying that biodegradation for these two compounds is low. This corresponds with the low biodegradation at $37 \%$ for SULFA and $29 \%$ for TET that was observed for both compounds. The half-lives that were obtained for all the antibiotics suggest that biodegradation was not very effective for them, even for AMO, which had the least half-life. Similar observations have been made by other researchers like Li and Zhang [18]

Different half-lives have been reported by various authors. Li and Zhang [18] studied the adsorption and biodegradation of selected antibiotics in activated sludge treating fresh and saline wastewaters. Amongst the studied antibiotics were the Fluoroquinolones and Sulphonamides. Their experimental run time was 48 hours. The calculated half-lives were: 92.4 and 111.8 hours for the fluoroquinolones, while Sulphonamides was 64.2 and 133.3 hours. In another study by Hoang et al. [31] on the fate of Fluoroquinolones in the coastal wetlands ecosystem, they evaluated their half-lives during biodegradation to be 22.2 to 25.6 days. They observed that the biodegradation of the Fluoroquinolones was poor. From both studies, it was observed that the adsorption of most of the studied compounds to sediments and other matrices was high, which could have prevented effective biodegradation.

Therefore, the removal of antibiotics in WWTPs constitutes a real challenge because as observed, the conventional treatment is not sufficiently efficient to completely remove them from wastewaters. Most of the WWPTs operate at an HRT that are lower than the half-lives as determined in this study. Furthermore, it is clear that most of the antibiotics were adsorbed to the sludge without a phase change. Therefore, it is important that the operating conditions for the WWTPs are optimised to improve removal of these micro-pollutants in wastewater.

\section{CONCLUSIONS}

The laboratory scale anaerobic reactor was employed to treat synthetic wastewater to explore the removal efficiency of five veterinary antibiotics. In a like manner, batch reactors were further used to evaluate the removal routes of the antibiotics.

The UASB reactor was operated continuously under mesophilic conditions to evaluate its performance with regards to the removal of organics and at the same time monitor biogas production. Organic loading rate (OLR) was varied between 2.8 to $9.2 \mathrm{~kg} . \mathrm{COD} \cdot \mathrm{m}^{-3} \cdot \mathrm{d}^{-1}$ while keeping the hydraulic retention time (HRT) constant at $12 \mathrm{~h}$. Chemical oxygen demand (COD) removal efficiency higher than $75 \%$ was achieved at an OLR of $9 \mathrm{~kg} \cdot \mathrm{COD} \cdot \mathrm{m}^{-3} \cdot \mathrm{d}^{-1}$, with a HRT of 12 hours. About $80 \%$ of the antibiotics were removed during the continuous processes, however, a distinctive pattern of removal was not observed.

With regards to the biodegradation, the current assumption that antibiotics do not degrade extensively under anaerobic conditions is correct. The study on the biodegradation revealed that biodegradation occurred alongside adsorption but to a lesser degree. Adsorption was about $80 \%$ for AMO, CIP, ENRO, and TET while for SULFA, it was $49 \%$. The compounds biodegradation was 29 to $38 \%$. The kinetic data 
showed that the antibiotics followed a first order kinetic model with half-lives that ranged from 6 to 77 days.

This study therefore lays the foundations for the development of efficient processes that might improve the removal of antibiotics.

\section{ACKNOWLEDGMENT}

The authors wish to thank the Durban University of Technology and the National Research Foundation (NRF) of South Africa for their support.

\section{REFERENCES}

[1] Chollom, M., Rathilal, S., Swalaha, F. and Bakare, B. (2018). Fate, transport, and toxicity of veterinary antimicrobials with an insight on Africa: A review. Ecology, Environment and Conservation, 24(3): 12011220.

[2] Zhang, M., Liu, Y.S., Zhao, J.L., Liu, W.R., He, L.Y., Zhang, J.N., Chen, J., He, L.K., Zhang, Q.Q., Ying, G.G. (2018). Occurrence, fate and mass loadings of antibiotics in two swine wastewater treatment systems. Science of the Total Environment, 639: 1421-1431. https://doi.org/10.1016/j.scitotenv.2018.05.230

[3] Puckowski, A., Mioduszewska, K., Lukaszewicz, P., Borecka, M., Caban, M., Maszkowska, J., Stepnowski, P. (2016). Bioaccumulation and analytics of pharmaceutical residues in the environment: A review. Journal of Pharmaceuticals and Biomedical Analysis, 127: 232-55. https://doi.org/10.1016/j.jpba.2016.02.049

[4] Gaskins, H.R., Collier, C.T., Anderson, D.B. (2002). Antibiotics as growth promotants: Mode of action. Animmal Biotechnology, 13(1): 29-42. https://doi.org/10.1081/ABIO-120005768

[5] Ronquillo, M.G., Angeles, H.J.C. (2017). Antibiotic and synthetic growth promoters in animal diets: Review of impact and analytical methods. Food Control, 72(Part B): 255-267. https://doi.org/10.1016/j.foodcont.2016.03.001

[6] Feng, L., Casas, M.E., Ottosen, L.D.M., Møller, H.B., Bester, K. (2017). Removal of antibiotics during the anaerobic digestion of pig manure. Science of the Total Environment, 603-604:

219-225. https://doi.org/10.1016/j.scitotenv.2017.05.280

[7] Gonzalez-Gil, L., Papa, M., Feretti, D., Ceretti, E., Mazzoleni, G., Steimberg, N., Pedrazzani, R., Bertanza, G., Lema, J. M. and Carballa, M. (2016). Is anaerobic digestion effective for the removal of organic micropollutants and biological activities from sewage sludge? Water Research, 102: 211-220. https://doi.org/10.1016/j.watres.2016.06.025

[8] Chollom, M., Rathilal, S., Swalaha, F., Bakare, B. (2018). Degradation of veterinary antibiotics from slaughterhouse wastewater using titanium dioxide as a catalyst. 10th International Conference on Sustainable Development and Planning, Siena, Italy, pp. 1743-3541.

[9] Barndõk, H., Hermosilla, D., Han, C., Dionysiou, D.D. Negro, C., Blanco, Á. (2016). Degradation of 1,4dioxane from industrial wastewater by solar photocatalysis using immobilized $\mathrm{NF}^{-\mathrm{TiO}_{2}}$ composite with monodisperse $\mathrm{TiO}_{2}$ nanoparticles. Applied Catalysis B: Environmental, 180: 44-52. https://doi.org/10.1016/j.apcatb.2015.06.015

[10] Chollom, M., Rathilal, S., Swalaha, F., Bakare, B., Tetteh, E.K. (2019). Comparison of response surface methods for the optimization of an upflow anaerobic sludge blanket for the treatment of slaughterhouse wastewater. Environmental Engineering Research, 25(1): 114-122. https://doi.org/10.4491/eer.2018.366

[11] Pérez, S., Eichhorn, P., Aga, D.S. (2005). Evaluating the biodegradability of sulfamethazine, sulfamethoxazole, sulfathiazole, and trimethoprim at different stages of sewage treatment. Environmental Toxicology and Chemistry: An International Journal, 24(6): 1361-1367. https://doi.org/10.1897/04-211R.1

[12] Kim, S., Eichhorn, P., Jensen, J.N., Weber, A.S., Aga, D.S. (2005). Removal of antibiotics in wastewater: effect of hydraulic and solid retention times on the fate of tetracycline in the activated sludge process. Environmental Science \& Technology, 39(15): 58165823. https://doi.org/10.1021/es050006u

[13] Chollom, M., Rathilal, S., Swalaha, F., Bakare, B., Tetteh, E.K. (2019). Anaerobic treatment of slaughterhouse wastewater: Evaluating operating conditions. WIT Transactions on Ecology and the Environment, 239: 251262. https://doi.org/10.2495/WS190221

[14] Jha, P., Kana, E.B.G., Schmidt, S. (2017). Can artificial neural network and response surface methodology reliably predict hydrogen production and COD removal in an UASB bioreactor? International Journal of Hydrogen Energy, 42(30): 18875-18883. https://doi.org/10.1016/j.ijhydene.2017.06.063

[15] Cao, W., Mehrvar, M. (2011) Slaughterhouse wastewater treatment by combined anaerobic baffled reactor and $\mathrm{UV} / \mathrm{H}_{2} \mathrm{O}_{2}$ processes. Chemical Engineering Research and Design, 89(7): 1136-1143. https://doi.org/10.1016/j.cherd.2010.12.001

[16] APHA-AWWA-WPCF. (1998). Standard methods for the examination of water and wastewater. 20th ed., American Public Health Association/American Water Works Association/Water Environment Federation, Washington, DC, USA.

[17] Wang, L., Qiang, Z., Li, Y., Ben, W. (2017). An insight into the removal of fluoroquinolones in activated sludge process: Sorption and biodegradation characteristics. Journal of Environmental Sciences, 56: 263-271. https://doi.org/10.1016/j.jes.2016.10.006

[18] Li, B., Zhang, T. (2010). Biodegradation and adsorption of antibiotics in the activated sludge process. Environment Science and Technology, 44(9): 3468-3472. https://doi.org/10.1021/es903490h

[19] Ferreira, V.R.A., Amorim, C.L., Cravo, S.M., Tiritan, M.E., Castro, P.M.L., Afonso, C.M.M. (2016). Fluoroquinolones biosorption onto microbial biomass: Activated sludge and aerobic granular sludge. International Biodeterioration \& Biodegradation, 110: 53-60. https://doi.org/10.1016/j.ibiod.2016.02.014

[20] Masse, D.I., Masse, L. (2000). Treatment of slaughterhouse wastewater in anaerobic sequencing batch reactors. Canadian Agricultural Engineering, 42(3): 131.

[21] Rizvi, H., Ahmad, N., Abbas, F., Bukhari, I.H., Yasar, A., Ali, S., Yasmeen, T., Riaz, M. (2015). Start-up of UASB reactors treating municipal wastewater and effect of temperature/sludge age and hydraulic retention time (HRT) on its performance. Arabian Journal of Chemistry, 
8(6):

780-786

https://doi.org/10.1016/j.arabjc.2013.12.016

[22] Vlyssides, A., Barampouti, E., Mai, S. (2009). Influence of ferrous iron on the granularity of a UASB reactor. Chemical Engineering Journal, 146(1): 49-56. https://doi.org/10.1016/j.cej.2008.05.011

[23] Chelliapan, S., Wilby, T., Sallis, P.J. (2006). Performance of an up-flow anaerobic stage reactor (UASR) in the treatment of pharmaceutical wastewater containing macrolide antibiotics. Water Research, 40(3): 507-16. https://doi.org/10.1016/j.watres.2005.11.020

[24] Meng, L.W., Li, X.K., Wang, K., Ma, K.L., Zhang, J. (2015). Influence of the amoxicillin concentration on organics removal and microbial community structure in an anaerobic EGSB reactor treating with antibiotic wastewater. Chemical Engineering Journal, 274: 94-101. https://doi.org/10.1016/j.cej.2015.03.065

[25] Chelliapan, S., Wilby, T., Yuzir, A., Sallis, P.J. (2011). Influence of organic loading on the performance and microbial community structure of an anaerobic stage reactor treating pharmaceutical wastewater. Desalination, 271(1-3): $257-264$ https://doi.org/10.1016/j.desal.2010.12.045

[26] Cheng, D.L., Ngo, H.H., Guo, W.S., Chang, S.W., Nguyen, D.D., Kumar, S.M., Du, B., Wei, Q., Wei, D. (2018). Problematic effects of antibiotics on anaerobic treatment of swine wastewater. Bioresource Technology, 263:

642-653

https://doi.org/10.1016/j.biortech.2018.05.010
[27] Dorival-García, N., Zafra-Gómez, A., Navalón, A., González-López, J., Hontoria, E., Vílchez, J.L. (2013). Removal and degradation characteristics of quinolone antibiotics in laboratory-scale activated sludge reactors under aerobic, nitrifying and anoxic conditions. Journal of Environmental Management, 120: 75-83. https://doi.org/10.1016/j.jenvman.2013.02.007

[28] Andreozzi, R., Caprio, V., Ciniglia, C., De Champdoré, M., Lo Giudice, R., Marotta, R., Zuccato, E. (2004). Antibiotics in the environment: Occurrence in Italian STPs, fate, and preliminary assessment on algal toxicity of amoxicillin. Environmental science \& technology, 38(24): 6832-6838. https://doi.org/10.1021/es049509a

[29] Zheng, W., Zhang, Z., Liu, R., Lei, Z. (2018). Removal of veterinary antibiotics from anaerobically digested swine wastewater using an intermittently aerated sequencing batch reactor. Journal of Environmental Sciences, 65: 8-17.

[30] Shi, Y.J., Wang, X.H., Qi, Z., Diao, M.-H., Gao, M.M., Xing, S.F., Wang, S.G., Zhao, X.C. (2011). Sorption and biodegradation of tetracycline by nitrifying granules and the toxicity of tetracycline on granules. Journal of Hazardous Materials, 191(1-3): 103-109. https://doi.org/10.1016/j.jhazmat.2011.04.048

[31] Hoang, T.T.T., Tu, L.T.C., Le, N.P., Dao, Q.P., Trinh, P.H. (2012). Fate of fluoroquinolone antibiotics in Vietnamese coastal wetland ecosystem. Wetlands Ecology and Management, 20: 399-408. https://doi.org/10.1007/s11273-012-9261-7 